\title{
CORRIGENDUM
}

\section{A randomized study of pomalidomide vs placebo in persons with myeloproliferative neoplasm-associated myelofibrosis and RBC-transfusion dependence}

A Tefferi, HK Al-Ali, G Barosi, T Devos, H Gisslinger, Q Jiang, J-J Kiladjian, R Mesa, F Passamonti, MF McMullin, V Ribrag, G Schiller, AM Vannucchi, D Zhou, D Reiser, J Zhong and RP Gale for the RESUME trialists

Leukemia (2017) 31, 1252; doi:10.1038/leu.2017.2

Correction to: Leukemia (2017) 31, 896-902; doi:10.1038/leu.2016.300; published online 18 November 2016

Following the online publication of this article, the authors noted that Dr McMullin was incorrectly excluded from the author list.
The complete author names are given above. Dr McMullin's affiliation is Department of Haematology, Queen's University, Belfast, UK. 